www.jmscr.igmpublication.org

Impact Factor 5.244

Index Copernicus Value: 83.27

ISSN (e)-2347-176x ISSN (p) 2455-0450

crossref DOI: _https://dx.doi.org/10.18535/jmscr/v4i10.76

Journal Of Medical Science And Clinical Research

IGM Publication

An Official Publication of IGM Publication

$\underline{\text { Research Article }}$

\title{
A Study on Knowledge and Practice of Menstrual Hygiene Among Menstruating Women of Age Group 15-44 Yrs in A Rural Area, Tamilnadu
} Authors

Vijayakeerthi. R ${ }^{1}$, Kalyani. P, Felix. A.J.W, Govindarajan.P.K

Department of Community Medicine, Rajah Muthiah Medical College,

Annamalai University, Chidambaram, Tamilnadu

*Corresponding Author

Dr R .Vijayakeerthi

Department of Community Medicine, Rajah Muthiah Medical College,

Annamalai University, Tamilnadu

Email: ramvijay50.vr@gmail.com,Phone No.: +919043756375

\begin{abstract}
Background: Menstruation in women is a normal physiological process and key sign of reproductive health. Poor menstrual hygiene has not yet been recognized as a problem in many developing countries. Proper menstrual hygiene is essential for one's own well being and development.

Objectives: To assess the knowledge and practice of menstrual hygiene in women of age group 15-44 yrs and to find out the relationship between knowledge and practice of menstrual hygiene.

Materials and Methods: A community based, cross sectional study done at South Pichavaram, Chidambaram, Tamilnadu among women of reproductive age for a period of 8 months from January to August 2016. Data was collected using validated, structured, pre tested questionnaire and analyzed using SYSTAT12 software.

Results: out of 337 study participants, 29.7\% had adequate knowledge about menstruation and menstrual hygiene and $46.6 \%$ had good level of menstrual hygiene practice. It was found that there was a positive correlation exists between knowledge level and practice of menstrual hygiene in the women.

Conclusion: Nearly $70 \%$ of the women were not having adequate knowledge about menstruation and menstrual hygiene. Nearly half of them were not having good practice during menstruation. Therefore there is a need to increase awareness about menstrual hygiene among the women by giving periodic health education. Keywords: Reproductive age, menstruation, knowledge, hygiene, practice.
\end{abstract}

\section{INTRODUCTION}

The reproductive life of women starts with the onset of menarche that occurs between 11 and 15 yrs with a mean age of 13 yrs. A woman menstruates for 3-5 days average (minimum of 2 days and maximum of 7 days) each month until menopause which accounts to approximately 2100 days \& equivalent to six yrs of her life of menstruation $^{1}$. Maintaining proper menstrual hygiene is important for one's own wellbeing and development. It requires access to adequate water for washing clothes, privacy to change their absorbents, clean \& safe absorbents, facilities to dispose the used absorbents. If any of these are not accessible, it leads to unhygienic practices. The areas of special concern include choice of the best female hygiene products, how often and when to change the feminine hygiene products, bathing care of the vulva and vagina as well as the 
supposed benefits of vaginal douching at the end of each menstrual period ${ }^{2}$.

But Social prohibition and negative attitude of parents in discussing the related issues openly have blocked the access of adolescent girls to right kind of information, especially in the rural and tribal communities ${ }^{3}$. Because of the lack of knowledge, they end up with repeated use of unclean menstrual absorbents, resulting in harboring of microorganisms that increase susceptibility to urinary, perineal, vaginal and pelvic infections ${ }^{4}$. If these infections are left untreated that will lead to several consequences like infertility, ectopic pregnancy, fetal wastage and prenatal infections, low birth weight babies and toxic shock syndrome ${ }^{5}$.

Women having better knowledge regarding menstrual hygiene and safe practices are less vulnerable to reproductive tract infections and its consequences $^{6}$. The knowledge, attitudes and practices regarding menstrual hygiene, which establishes at adolescence, are usually followed throughout life and also passed on to the next generation. Therefore faulty practices pertaining to menstruation will affect health of large number of women in reproductive age group. Hence it is necessary to assess knowledge and the practices of mother as well as other female family members regarding the menstrual hygiene.

This study was undertaken to assess the knowledge and practice of menstrual hygiene among the reproductive women of rural area of South Pichavaram, Chidambaram and to find out the relationship between knowledge and practice.

\section{MATERIALS AND METHOD}

The community based cross sectional study was conducted in a rural area of South Pichavaram, Tamilnadu. The area comprises of a population of 1620 consisting 350 households. The study population comprised of 337 women of reproductive age group ie 15-44 yrs, residing in that area. The ethical clearance was obtained from the institute. Also prior informed consent was obtained from eligible participants. The study was conducted on 337 women for a period of 8 months from January -august 2016.

A pilot study was conducted on 50 women and out of them $30 \%$ had inadequate knowledge. Keeping this as prior information, $5 \%$ as absolute precision and level of significance as $5 \%$, the required sample size was 323 . However 337 women were included for the study using convenient sampling. A structured, pretested questionnaire was used and its content was validated in the pilot study. The women who have attained menarche, menstruating and gave consent to participate in the study were included. Those women who had undergone hysterectomy and pregnant women were excluded. There were 8 questions to assess the knowledge about menstruation and menstrual hygiene consisting of questions on meaning of menstrualtion, organs involved, normal duration, consequence of poor menstrual hygiene and nutrient lost during menstruation. The correct response for each question was awarded 1 mark and the remaining as 0 . Hence the minimum and maximum score that can be acquired by the respondent were 0 and 8 respectively. Scores 1-3, 4-6, 7-8 points were graded as poor, fair, good knowledge respectively.

There were 11 questions to assess the level of practice of menstrual hygiene that included type of absorbent used, number of times of absorbent changed per day, reusing of absorbent, material used to wash the absorbent, place of drying, taking bath during menstruation, number of times of cleaning the genitalia and method of disposal. Here the minimum score that can be acquired by the respondent was 0 and maximum score 11 . Scores $0-5,5-7,8-11$ points were graded as poor, fair and good practice respectively.

After completion of the data, the information gathered was entered in Microsoft excel 2007 and statistical analysis was done using SYSTAT 12 software and expressed using descriptive statistics and Pearson correlation coefficient.

\section{RESULTS}

Table 1 depicts the socio demographic details of the study subjects. Majority $48.9 \%$ of the study 
participants were in the age group 15-24 yrs and nearly half of the respondents $(55.2 \%)$ were married and $43.3 \%$ were unmarried. $36.5 \%$ of the study participants have completed high school followed by $23.1 \%$ have completed degree/ diploma. $45.4 \%$ of the study participants were unemployed and $44.2 \%$ of the respondent's family monthly income were between Rs.5001-10,000.

Table 2 shows the age at menarche and menstrual regularity. The age of menarche varied from 11$16 y r s$ and majority $(85.7 \%)$ of women attained menarche at the age of 13-15yrs followed by $10.4 \%$ at the age of $11-12 \mathrm{yrs}$ and $3.9 \%$ at the age of 16 . The mean age of menarche of the study respondents is $13.45 \mathrm{yrs} .84 .0 \%$ of the study participants had their periods every month regularly while $16 \%$ of respondents had irregular pattern of menstruation.

Table 3 shows the knowledge of study participants about menstruation and menstrual hygiene. All women were aware about the normal duration of menstrual cycle and $96.4 \%$ knew the normal duration of menstruation. Nearly half of the women $(55.5 \%)$ knew source of menstruation but only $26.7 \%$ were aware that the menstruation is caused by the hormonal changes. $90.2 \%$ responded that the sanitary pad is the ideal menstrual absorbent and $51.3 \%$ of respondents were aware that poor menstrual hygiene leads to reproductive tract infection and $19.3 \%$ responded both i.e reproductive tract infection and misfortune to home are the consequences of poor menstrual hygiene. Table 4 shows overall $45.7 \%$ of women had fair knowledge and only $29.7 \%$ of women had good knowledge about menstruation and menstrual hygiene.

Regarding the menstrual hygiene practices it was found that $68.8 \%$ of the study participants used disposable sanitary pads as the absorbent, $21.7 \%$ of the women used old cloth and 9.5\% used both cloth and pad for managing menstruation. $88.4 \%$ of women in this study had the habit of changing pad 2-3 times/day. All the study participants who used cloth during their menstruation (31.2\%) had the habit of reusing the cloth and among them $21.1 \%$ of the participants use water and soap and only $9.8 \%$ use antiseptics to wash the cloth. $26.7 \%$ of the women who reuse the cloth dried the washed cloth under sunlight and $4.5 \%$ dry the cloth inside the bathroom.

All the study participants had the habit of taking bath every day during menstruation.53.7\% of respondents had the practice of cleaning external genitalia frequently and $61.4 \%$ of respondents had the habit of washing their hand and genitalia only with water while $25.8 \%$ of respondents washed their hands with soap and water. Only $12.8 \%$ of the study participants used antiseptic for washing. $63.8 \%$ of respondents wash their genitalia in front to back direction. $78.6 \%$ of respondents had the practice of burning or burying the absorbent as shown in the table 5 . Table 6 shows that $50.7 \%$ of women followed fair hygienic practices while $46.6 \%$ of women followed good hygienic practices during menstruation. There was a positive correlation exists between knowledge and practice among the study population as shown in the table no 7.

Table No.1 Sociodemographic Profile of The Study Population

\begin{tabular}{|c|c|c|}
\hline 1)AGE & $\mathrm{NO}$ & PERCENTAGE \\
\hline $15-19$ & 97 & 28.8 \\
\hline $20-24$ & 68 & 20.1 \\
\hline $25-29$ & 46 & 13.6 \\
\hline $30-34$ & 33 & 9.8 \\
\hline $35-39$ & 50 & 14.8 \\
\hline $40-44$ & 43 & 12.8 \\
\hline \multicolumn{3}{|l|}{ 2)MARITAL STATUS } \\
\hline UNMARRIED & 146 & 43.3 \\
\hline MARRIED & 186 & 55.2 \\
\hline WIDOWER & 5 & 1.5 \\
\hline \multicolumn{3}{|c|}{ 3)EDUCATIONAL STAUS } \\
\hline ILLITERATE & 4 & 1.2 \\
\hline PRIMARY & 61 & 18.1 \\
\hline HIGH SCHOOL & 123 & 36.5 \\
\hline $\begin{array}{l}\text { HIGHER } \\
\text { SECONDARY }\end{array}$ & 71 & 21.1 \\
\hline DEGREE/DIPLOMA & 78 & 23.1 \\
\hline \multicolumn{3}{|c|}{ 4)OCCUPATIONAL STATUS } \\
\hline UNEMPLOYED & 153 & 45.4 \\
\hline EMPLOYED & 73 & 21.7 \\
\hline STUDENT & 111 & 32.9 \\
\hline \multicolumn{3}{|c|}{ 5)MONTHLY INCOME } \\
\hline $3000-5000$ & 18 & 5.3 \\
\hline $5001-10,000$ & 149 & 44.2 \\
\hline $10,001-15,000$ & 62 & 18.4 \\
\hline $15,001-20,000$ & 61 & 18.1 \\
\hline $20,001-25,000$ & 12 & 3.6 \\
\hline$>25,001$ & 35 & 10.4 \\
\hline
\end{tabular}


Table No 2.-Distribution Of Study Participants

By Age At Menarche

\begin{tabular}{|c|c|c|}
\hline AGE AT MENARCHE & NO & PERCENTAGE \\
\hline 11 & 4 & 1.2 \\
\hline 12 & 31 & 9.2 \\
\hline 13 & 170 & 50.4 \\
\hline 14 & 86 & 25.5 \\
\hline 15 & 33 & 9.8 \\
\hline 16 & 13 & 3.9 \\
\hline MENSTRUAL & & \\
REGULARITY & & \\
\hline REGULAR & 283 & 84.0 \\
\hline IRREGULAR & 54 & 16.0 \\
\hline
\end{tabular}

Mean age at menarche is $13.45 \mathrm{yrs}$.

Table No 3: Knowledge Regarding Menstruation \& Menstrual Hygiene

\begin{tabular}{|c|c|}
\hline QUESTIONS & RESPONSE \\
\hline $\begin{array}{l}\text { what } \\
\text { menstruation? }\end{array}$ & $\begin{array}{l}\text { urethral bleeding }(13.9 \%) \\
\text { cyclical uterine bleeding }(46.0 \%) \\
\text { don't know }(40.1)\end{array}$ \\
\hline $\begin{array}{ll}\text { cause } & \text { for } \\
\text { menstruation } & \end{array}$ & $\begin{array}{l}\text { dietary change }(30.3 \%) \\
\text { hormonal change }(26.7 \%) \\
\text { behavioral change }(0.6 \%) \\
\text { don't know }(42.4 \%)\end{array}$ \\
\hline $\begin{array}{l}\text { organs responsible } \\
\text { for menstruation }\end{array}$ & $\begin{array}{l}\text { Breasts }(0.3 \%) \\
\text { ovary \& uterus }(55.5 \%) \\
\text { vulva \& vagina }(9.8 \%) \\
\text { don't know }(34.4 \%)\end{array}$ \\
\hline $\begin{array}{l}\text { normal menstrual } \\
\text { cycle }\end{array}$ & $25-28$ days $(100 \%)$ \\
\hline $\begin{array}{l}\text { average duration of } \\
\text { menstruation }\end{array}$ & $\begin{array}{l}<2 \text { days }(3.6 \%) \\
2-7 \text { days }(96.4 \%)\end{array}$ \\
\hline $\begin{array}{l}\text { ideal type of } \\
\text { menstrual absorbent }\end{array}$ & $\begin{array}{l}\text { Cloth }(9.8 \%) \\
\text { sanitary pad(90.2\%) }\end{array}$ \\
\hline $\begin{array}{l}\text { poor menstrual } \\
\text { hygiene leads to }\end{array}$ & $\begin{array}{l}\text { reproductive tract infection }(51.3 \%) \\
\text { misfortune to home }(13.0 \%) \\
\text { both }(19.3 \%) \\
\text { general body infection }(13.4 \%) \\
\text { cancer }(3.0 \%)\end{array}$ \\
\hline $\begin{array}{l}\text { nutrient lost during } \\
\text { menstruation }\end{array}$ & $\begin{array}{l}\text { Vitamins }(9.8 \%) \\
\text { Iron }(28.2 \%) \\
\text { Fat }(9.2 \%) \\
\text { don't know }(52.8 \%)\end{array}$ \\
\hline
\end{tabular}

Table No 4. Knowledge Level Of Respondents About Menstruation And Menstrual Hygiene

\begin{tabular}{|c|c|c|}
\hline LEVEL OF KNOWLEDGE & NO & PERCENTAGE \\
\hline POOR(1-3 POINTS) & 83 & 24.6 \\
\hline FAIR(4-6 POINTS) & 154 & 45.7 \\
\hline GOOD(7-8 POINTS) & 100 & 29.7 \\
\hline TOTAL & 337 & 100 \\
\hline
\end{tabular}

Table No 5. Practice Of Menstrual Hygiene

Among The Study Participants.

\begin{tabular}{|c|c|}
\hline QUESTIONS & RESPONSE \\
\hline type of absorbent & $\begin{array}{l}\text { old cloth }(21.7 \%) \\
\text { sanitary pad }(68.8 \%) \\
\text { both }(9.5 \%)\end{array}$ \\
\hline $\begin{array}{l}\text { storage of unused } \\
\text { absorbent }\end{array}$ & $\begin{array}{l}\text { Bathroom }(12.2 \%) \\
\text { dress cabinet }(50.4 \%) \\
\text { open shelves }(11.3 \%) \\
\text { secret place }(26.1 \%)\end{array}$ \\
\hline $\begin{array}{l}\text { change of pads/cloth per } \\
\text { day }\end{array}$ & $\begin{array}{l}\text { One }(2.4 \%) \\
\text { Two }(50.4 \%) \\
\text { Three }(38.0 \%) \\
\text { Four }(9.2 \%)\end{array}$ \\
\hline reuse of cloth & $\operatorname{Yes}(31.2 \%)$ \\
\hline $\begin{array}{l}\text { used for washing the } \\
\text { cloth }\end{array}$ & $\begin{array}{l}\text { only water }(0.3 \%) \\
\text { water with soap }(21.1 \%) \\
\text { antiseptics with water(9.8\%) } \\
\text { not applicable }(68.8 \%)\end{array}$ \\
\hline drying of cloth & $\begin{array}{l}\text { Bathroom }(4.5 \%) \\
\text { under sunlight }(26.7 \%) \\
\text { not applicable }(68.8 \%)\end{array}$ \\
\hline taking bath per day & $\begin{array}{l}\text { one time }(56.1 \%) \\
\text { twice a day }(43.9 \%) \\
\text { never take bath }(0 \%)\end{array}$ \\
\hline wash of genitalia per day & $\begin{array}{l}2-3 \text { times }(46.3 \%) \\
4 \text { or }>4 \text { times }(53.7 \%)\end{array}$ \\
\hline $\begin{array}{llr}\text { material } & \text { used } & \text { for } \\
\text { washing } & \text { hands } & \& \\
\text { genitalia } & & \end{array}$ & $\begin{array}{l}\text { water alone }(61.4 \%) \\
\text { water with soap }(25.8 \%) \\
\text { water with antiseptics }(12.8 \%)\end{array}$ \\
\hline $\begin{array}{l}\text { disposing method of } \\
\text { used absorbent }\end{array}$ & $\begin{array}{l}\text { burning/burying(78.6\%) } \\
\text { domestic waste }(21.4 \%)\end{array}$ \\
\hline $\begin{array}{l}\text { direction of washing } \\
\text { genitalia }\end{array}$ & $\begin{array}{l}\text { front to } \operatorname{back}(63.8 \%) \\
\text { front to back \& back to front }(35.6 \%) \\
\text { side to side }(0.6 \%)\end{array}$ \\
\hline
\end{tabular}

Table No 6 Level Of Practice Of Menstrual Hygiene Among Study Participants

\begin{tabular}{|c|c|c|}
\hline LEVEL OF PRACTICE & NO & PERCENTAGE \\
\hline POOR(<5 POINTS) & 9 & 2.7 \\
\hline FAIR $(5-7$ POINTS) & 171 & 50.7 \\
\hline GOOD $(8-11$ POINTS) & 157 & 46.6 \\
\hline TOTAL & 337 & 100 \\
\hline
\end{tabular}

MEAN-7.36 SD-1.01.

Table No.7. Correlation Between Knowledge And Practice Of Menstrual Hygiene

\begin{tabular}{|l|l|l|}
\hline & $\begin{array}{l}\text { PEARSON } \\
\text { CORRELATION } \\
\text { COEFFICIENT }\end{array}$ & KNOWLEDGE \\
\hline \multirow{2}{*}{ PRACTICE } & $\mathrm{r}$ & 0.457 \\
\cline { 2 - 3 } & $\mathrm{p}$ & $<0.001$ \\
\hline
\end{tabular}




\section{DISCUSSION}

In the present study, majority of women $85.7 \%$ attained menarche at the age of 13-15yrs followed by $35(10.4 \%)$ at the age of $11-12$ yrs and $13(3.9 \%)$ at the age of $16 \mathrm{yrs}$. The mean age of menarche among the study participants was $13.45 \mathrm{yrs}$. Similarly, a study by Sangeetha Balamurgan et $\mathrm{al}^{7}$ found that maximum number of girls attained menarche between 13-15yrs $(60 \%)$ and mean age of menarche of the respondents was $13.15 \mathrm{yrs}$. $84 \%$ of the respondents had regular cycles and $16 \%$ of women had irregular cycles which was similar to the study report by Bhavik Rana et $\mathrm{al}^{8}$ where $19 \%$ of the study participants had irregular menses.

It was observed from the present study, among 337 women majority $45.7 \%$ of the study participants had average knowledge about menstruation and menstrual hygiene. $29.7 \%$ and $24.6 \%$ of women had good and poor knowledge respectively. Studies conducted by other authors like Adhikari $\mathrm{P}$ et $\mathrm{al}^{9}$ and $\mathrm{LawanUM}^{10}$ et al had observed similar findings. Nearly half of the respondents $55.5 \%$ knew the source of menstruation. In contrast to the current finding, studies carried out by Jugal et $\mathrm{al}^{11}(29.1 \%)$, Adhikari P et $\mathrm{al}^{9}(25.3 \%)$ and Adwitiya Das et al ${ }^{12}$ $(20.8 \%)$ showed that the study participants had low level of knowledge about the source of menstruation. Regarding the normal duration of menstruation $96.4 \%$ of women had given correct response and this is consistent with findings from the studies by Kamath $\mathrm{R}$ et $\mathrm{al}^{13}(92 \%)$ and Karthik $\mathrm{R}$ et $\mathrm{al}^{14}(92 \%)$.

$50.7 \%$ of women in current study followed moderate hygienic practices and $46.6 \%$ of women followed good hygienic practice which is contrast to the study done by Patilsudha rani ${ }^{15}$ that showed $36.3 \%$ of women practiced moderate and $26.2 \%$ of women practiced good hygiene. In the present study $68.8 \%$ of respondents used sanitary pad, $21.7 \%$ of women used old cloth and $9.5 \%$ used both cloth and pad which is in concordance with the study done by Kamakhya kumar et $\mathrm{al}^{16}$. Whereas the study done by Sangeetha Balamurgan $^{7}$ revealed lower usage of sanitary pads in which $52 \%$ of women used cloth as menstrual absorbent, $35 \%$ of women used pad and the rest $13 \%$ used both. The Government of India had launched a scheme for the promotion of menstrual hygiene among adolescent girls in rural areas of the country. The main focus of the scheme is to increase awareness among adolescent girls on menstrual hygiene, built self-esteem and increase access and use of high quality sanitary pads by adolescent girls in rural areas ${ }^{17}$. The pads were given at schools and also in the community by anganwadi worker. This scheme of supply of sanitary pads at low cost by the Government had a great impact in improvement of menstrual hygiene by the adolescent girls and this practice makes them to carry through rest of their reproductive life.

It was observed from the present study, among the study participants who used cloth, all had the habit of reusing the cloth $(31.2 \%)$ for the next menstrual cycle. $21.1 \%$ used water and soap for washing the cloth and $26.7 \%$ of women dried the washed cloth under sunlight which is in concordance with the study done by Patilsudha rani ${ }^{15}$.

$88.4 \%$ of women in this study had the habit of changing pad 2-3 times/day. Similar result has been reported by the studies done by Adwitiya Das et $\mathrm{al}^{12}(83.0 \%)$ and Anjuade ${ }^{18}(91.2 \%)$. All the study participants had the habit of taking bath every day during menstruation. Anju Ade et $\mathrm{al}^{18}$ reported similar finding in their study.

To prevent infections, it is essential to maintain good menstrual hygiene which requires frequent washing of private parts with soap or antiseptic and water. $53.7 \%$ of the study respondents in our study had the practice of cleaning external genitalia frequently and $61.4 \%$ of women use only water for washing. The study conducted by Patilsudha rani $^{15}$ also reported similarly, where $58.3 \%$ wash frequently and $62.3 \%$ of women use water only for cleaning.

Among the 337 women, $78.6 \%$ of them burn or bury the used absorbents and only $21.4 \%$ of women disposed it by adding to the domestic waste. It was belief that the used absorbents shouldn't be seen by any other family persons 
especially male or otherwise it may bring misfortune to the family, so it was their custom either to bury or burn the used absorbent. Similar finding was reported in the study done by Hema Priya $S$ et al $^{19}$ where majority of the study participants $(60.8 \%)$ burn their used absorbents and $29 \%$ of girls disposed in domestic waste.

\section{CONCLUSION AND RECOMMENDATIONS}

Nearly $70 \%$ of the women were not having adequate knowledge about menstruation and menstrual hygiene. Nearly half of them were not having good practice during menstruation. Hence health education should be given to all women to gain adequate knowledge about menstruation and its management. All women should be encouraged to use the sanitary pads for which these pads should be affordable to every women of our society.

\section{REFERENCES}

1. William $\mathrm{F}$ and Ganong MD. The female Reproductive system. Review of Medical Physiology .Lange 21 ${ }^{\text {st }}$ Ed.2003:437-451.

2. Menstrual Hygiene. Feminine Hygiene, Gynaecology and Menstruation Information, Resources and Products for Dads and Husband. http://menstrualhygiene.com.

3. Mudey AB, Keshwani N, Mudey GA, Goyal RC. A cross sectional study on the awareness regarding safe and hygienic practices amongst school going adolescent girls in the rural areas of Wardha district. Global journal of Health Science.2010; 2(2):225-231.

4. Garg R, Goyal S, Gupta S. India moves towards menstrual hygiene: Subsidized sanitary Napkins for Rural Adolescent Girls-Issues and challenges. Maternal child health journal. 2012;16(4):767-774.

5. Ram R, Bhattacharya SK, Bhattacharya K et al. Reproductive tract infection among female adolescents. Indian journal of Community Medicine. 2006;31(1):32-33.

6. Dasgupta A, Sarkar M. Menstrual hygiene: how hygienic is the adolescent girl? Indian
Journal of Community Medicine.2008; 33(2): 77-80.

7. S Sangeetha Balamurugan, SS Shilpa, Sheethal Shaji. A community based study on menstrual hygiene among reproductive age group women in a rural area, Tamil Nadu. Journal of Basic and Clinical Reproductive Sciences. 2014;3(2):83-87.

8. Bhavik Rana, Arpit Prajapati, K.N.Sonaliya, Venu Shah, Mansi Patel, Asha Solanki. An assessment of menstrual hygiene practices amongst adolescent females at Kheda District of Gujarat state, India. Healthline journal.2015;6(1):23-29.

9. Adhikari P, Kadel B, Dhungel SI, Mandal A .Knowledge and practice regarding menstrual hygiene rural adolescent girls of Nepal. Kathmandu University Medical Journal. 2009; 5(19): 382-386.

10. Lawan UM, Nafisa Wali Yusuf, Aisha Bala Musa. Menstruation and menstrual hygiene amongst adolescent school girls in Kano, Northwestern Nigeria. African Journal of Reproductive Health. 2010; 14(3):201-207.

11. Juyal R, Kandpal SD, Semwal J, Negi KS . Practices of Menstrual Hygiene among adolescent girls in a district of Uttarakhand. Indian Journal of Community Health. 2012;24(2):124-128.

12. Adwitiya Das, Aparajita Dasgupta, Rahul Biswas, Dipanjan Ray, Arnab Ghosal, Trinath Sarkar. Knowledge and practices regarding menstrual management among women in a remote village of Eastern India. International Journal of Biomedical \& Medical Research.2014; 5(3):41904196.

13. Kamath R, Ghosh D, Lena A, Chandrasekaran V. A study on knowledge and practices regarding menstrual hygiene among rural and urban adolescent girls in Udupi Taluk, Manipal, India. Global Journal of medicine and Public Health. 2013;2(4):1-9. 
14. Kartik Ramachandra, Sahana Gilyaru, Adarsh Eregowda, Sreekrishna Yathiraja. A study on knowledge and practices regarding menstrual hygiene among urban adolescent girls. International Journal of Contemporary Pediatrics. 2016 ;3(1):142145.

15. Patil Sudha Rani. Knowledge and Practices of Menstrual Hygiene among married adolescents and young women in Chittoor District of Andra Pradesh:India. Journal of Nursing and Health Science. 2014;3(2):06-15.

16. Kamakhya Kumar, Arunima Datta, Arup Bandyopadhyay. Knowledge, problems and practices of adolescent girls during menstruation. Indian Medical Gazatte. 2015;85-88.

17. NRHM Newsletter, Promotion of menstrual hygiene.2011;6(3).

18. Anju Ade, Ramesh Patil. Menstrual Hygiene and Practices of rural adolescent girls of Raichur. International Journal of Biological \& Medical Research. 2013;4(2):3014-2017

19. Hema Priya S, Nandi Partha, Seetharaman N, Narayan k, Anantahasubramanian, Lokeshmaran A. A study of Menstrual Hygiene Practices and associated symptomatic genitourinary illness among adolescent girls in Rural Puducherry. Int.J.Preven.Curat.Comm.Med.2015;1(4):1 $0-19$. 